\title{
ComSciCon-Michigan •
}

\section{Impacts of Formal Science}

Communication Training

for Graduate Students \&

\section{Postdoctoral Researchers:}

\section{A case study from \\ ComSciCon-Michigan}

Stephanie J. Deppe (Hamilton) ${ }^{1}$, Sarah Kearns ${ }^{2}$, Jessica Y. Chen ${ }^{3}$,

Ellen K.W. Brennan ${ }^{4}$, Sara A. Hugentobler ${ }^{5}$

${ }^{1}$ University of Michigan, Department of Physics,

2University of Michigan, Program in Chemical Biology,

${ }^{3}$ University of Michigan, Neuroscience Graduate Progaram,

${ }^{4}$ University of Michigan, Neuroscience Graduate Program,

${ }^{5}$ Michigan State University, Department of Integrative Biology

Published on: Nov 03, 2021

License: Creative Commons Attribution 4.0 International License (CC-BY 4.0). 


\section{ABSTRACT}

ComSciCon-Michigan (CSC-MI) is a local installment of the Communicating Science Conference (ComSciCon), an annual workshop led by graduate students to provide science communication training. Since starting in 2018, CSC-MI workshops have featured local science communication experts, hands-on and interactive sessions, and informal networking events that allowed attendees to strengthen communication skills. Here, we present an analysis of pre- and post-conference survey data collected from CSC-MI attendees from 2018-2020 to gauge the impact of our conference. Attendees were asked before and after the formal training events to self-report their confidence and ability to communicate their science to three different audiences: popular science outlets, the general public, and other scientists. We found a significant increase in attendees' overall confidence after receiving training across all three audiences. In addition, we asked participants to write a 2-3 sentence summary about their research as part of the pre-/post-survey. We found that text readability scores decreased (i.e., text became more readable) though the number of difficult words used and the reading grade level of the research summaries remained constant. In conclusion, conference survey data showed that CSC-MI has had a measurable impact on the self-reported confidence and technical ability of early career researchers in the Midwest region to communicate their science more effectively.

\section{Introduction}

Scientists mandate clear and effective communication in order to teach and share methods with students and colleagues, to convince other scientists of the veracity of their findings, and to perpetuate and grow public support of their work. Effective science communication has become more important than ever in light of a growing distrust of science and scientists in the public eye, where facts and data are not enough to significantly affect people's perspectives (․ㅡollier, 2017; Hayhoe, 2018; Kabat,2017; Rutjens et al.,2018). Instead, compelling narratives that tap into people's values make science more approachable and persuasive (Bilandizic et al.,2020; Constant \& Roberts,2017;_(Shermer,_2017). Many programs, fellowships, and educational programs aim to tackle some of these issues in communicating science. Often these types of science communication organizations and programs emerge from grassroots efforts to connect to the local community or provide training for career development. However, at the graduate level, course work and requirements on communication are lacking (Brownell et al.,_2013; Denecke et al.,2017; Kuehne et al.,_ 
2014). While science outreach initiatives can provide excellent training and experimental opportunities in communication, particularly when student-led, these are not well established at every institution. Graduate school is a phase of a scientist's education when professional development training in communication can have the largest impact, both in their immediate work and enduring throughout their career (Dilger \& McKeith,2015; Hatcher,2014; Laursen et al.,2012).

Communicating Science Conference (ComSciCon) workshops intend to provide professional development services and empower early career scientists to better communicate with experts outside their own field and with the general public. Based on the annual national events, local ComSciCon chapter workshops have been popping up around the world. These local workshops amplify the effect of the national workshop through targeted replication in regional communities. For early career scientists at either the graduate student or postdoctoral level, key outcomes of the local workshops include intensive professional development experiences for the attendees publication of writing and other materials produced by attendees during the workshop, and sustainable regional networks of early career scientists committed to an expansive vision of scientists' responsibility to interact with the public. Past ComSciCon programs in other locations have demonstrated that the impact of the local workshop programs have the capacity to propagate far beyond their attendee groups. These impacts can spread through keynote lectures open to the general public held in coordination with the workshop program, the reach of the publication outlets for the resulting written works, and the activities of new science outreach organizations founded by workshop participants. Moreover, connecting scientists to their local community increases the impact that their science communication can have by increasing perceived trustworthiness and authenticity (․ㅏske et al.,2007; Kahan, 2017;

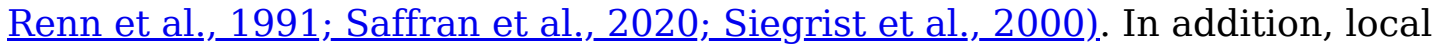
workshops can more readily meet the demand of graduate students for science communication training (. (O'Keeffe \& Bain, 2018).

ComSciCon-Michigan (CSC-MI) is one example of the many local workshops. Started in 2018, the workshops are designed to be a two-day program where early career scientists in STEM fields from lower Michigan and the surrounding midwest gather to discuss, develop, and enact best practices in science and technical communication. Each year, the program consists of several panel sessions with invited professional science communicators, writing sessions for participants to hone their skills, structured in-person peer-review and expert-review of writing, and pop talks where participants practice their science communication skills through one-minute 
introductions to their scientific research. During the workshop itself, time is allocated for networking with science communication experts and developing science outreach collaborations with fellow attendees and invited speakers. The wide range of topics for panels and interactive breakout sessions have included science illustration, K-12 education, improvisation and stand-up, science policy, website design, news reporting, and ethics in communication. Along with working with individuals from the community, CSC-MI builds community partnerships among groups and organizations in and external to academia.

Thus far, CSC-MI has provided training to $>150$ researchers and facilitated connections with $>50$ local science communication experts within the 2018, 2019, and 2020 sessions. Colloquially and anecdotally, the CSC-MI workshop has had great success boosting attendees excitement and confidence in science communication. In this study, we determined the measurable impact of CSC-MI workshop on the science communication skills of attendees. To do this, we utilized a pre- and post-survey where attendees were asked to self-report their confidence on a scale from 1 to 9 in their ability to communicate their science to three different audiences: submitting a written piece to a popular science outlet, engaging with the general public, and interacting with other scientists. Using the Wilcoxon signed rank test for paired samples to compare the overall distribution of confidence scores before and after receiving training, we found a significant increase in attendees' confidence with p-values $\mathrm{p}<0.01$ across all three audiences. A Cliff's delta test to measure the overlap between the "before" and "after" score distributions found less than $40 \%$ overlap (and as little as $21 \%$ overlap) across the three audiences. We also found a significant increase $(p<0.005)$ in each individual's confidence across all three audiences, with a median increase of 0.5-1.0 points on a 9-point scale. Finally, we asked attendees to write a 2-3 sentence research description for both the public and other scientists and found a trend toward more readable descriptions after receiving training.

\section{Methods and Results}

Each year, CSC-MI attendees are asked to fill out an evaluation survey based on that used for the ComSciCon-Flagship conference prior to attending the workshop and again after receiving training at the workshop. In the survey, attendees could optionally report their degree and number of years of science communication experience (Figure 1). Attendees were also asked for their permission to use their responses in pre- and post-workshop reports on our website and other promotional or 
educational materials, knowing that identifying information would only be used to link pre- and post- survey results for analysis and excluded otherwise. We received 151 matched pre- and post-workshop survey responses for which attendees consented to the use of their data for this study across three years of CSC-MI (2018-2020). Since participants were notified that their identifying information would not be used for anything but matching pre- and post-workshop survey responses and that their answers would be anonymized and used for statistical purposes, similar to the study

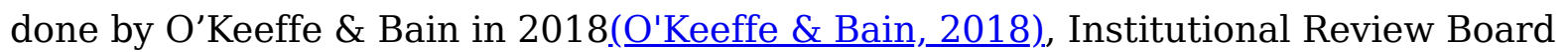
approval was not required. Specific survey wording can be found in the

\section{Supplementary Materials.}




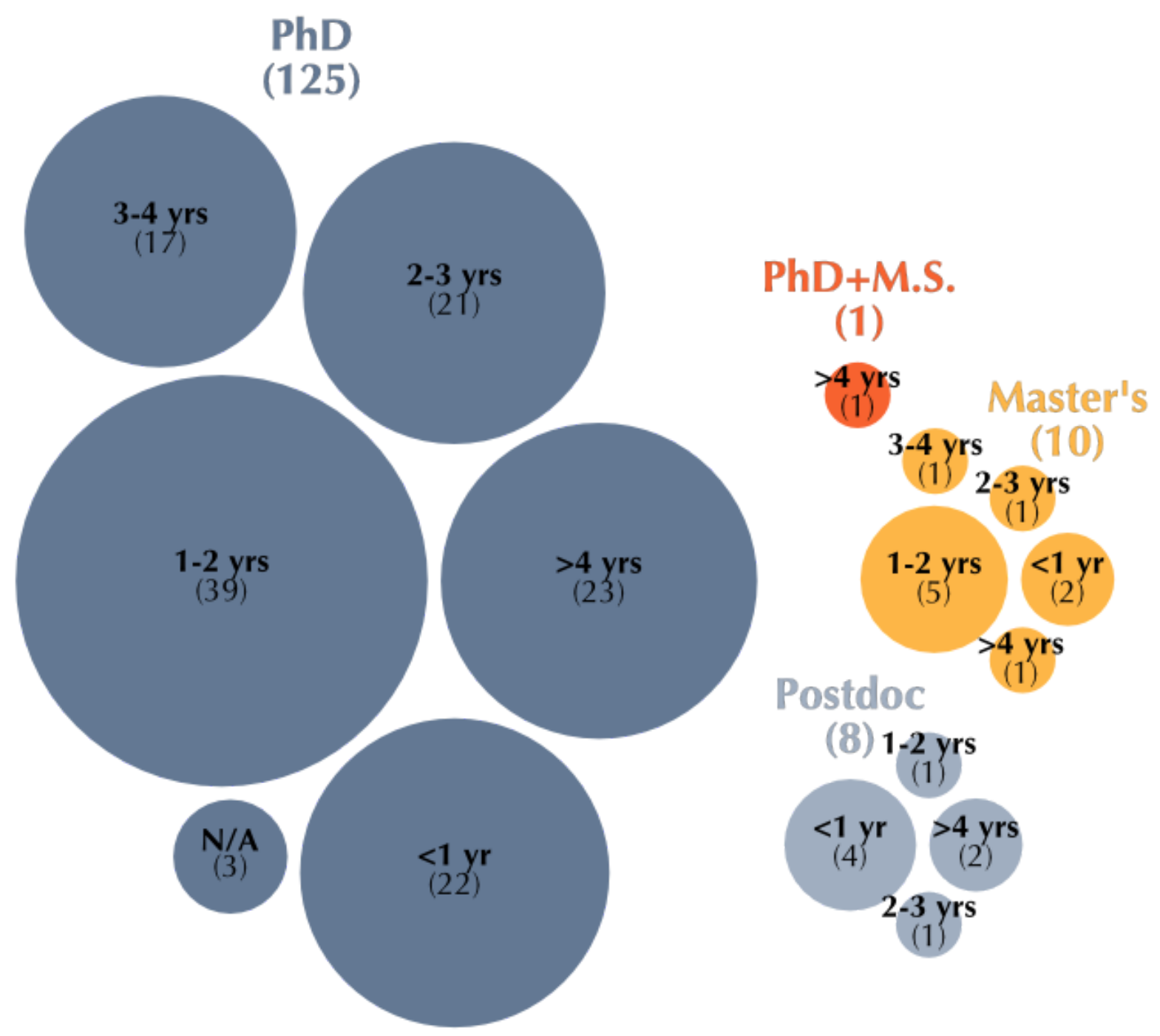

Figure 1. 144 attendees who responded to the demographics portion of the survey (of the total 151), sorted by degree and years of experience in science communication. The area of each circle is scaled by the number of attendees in each category and grouped by degree.

A major goal of CSC-MI is to provide attendees with training so they feel more confident approaching science communication activities (such as communicating with various audiences or pitching a piece of writing for publication). Therefore, a measure of success for the workshop is an increase in attendees' self-reported confidence in these activities after receiving training. Our pre- and post-workshop surveys asked attendees to rank their confidence on a scale from 1 (least confident) to 9 (most confident) in 3 situations as follows: 
1. Submitting a popular science article for publication

2. Communicating with the general public

3. Communicating with other scientists

We used the Mann-Whitney U-test to determine whether attendee confidence in the three stated situations increased significantly, based on the aggregated, unpaired data. The null hypothesis tested by the Mann-Whitney U-test states that a randomly selected score from the post-workshop survey responses has an equal probability of being less than and greater than a randomly selected score from the pre-workshop survey responses. In each of the three situations stated above, attendees indicated that they were significantly more confident after the workshop when compared to before (all pvalues<0.001). For each situation, we also calculated the Cliff's delta score, which measures the overlap of the pre- and post-workshop score distributions and ranges from -1 to 1 , where 0 indicates $100 \%$ overlap. We found the Cliff's delta scores to be $0.38,0.32$, and 0.21 for each of the three situations, respectively, which also indicates increases in attendees' confidence levels. Results are summarized in Figure 2. 


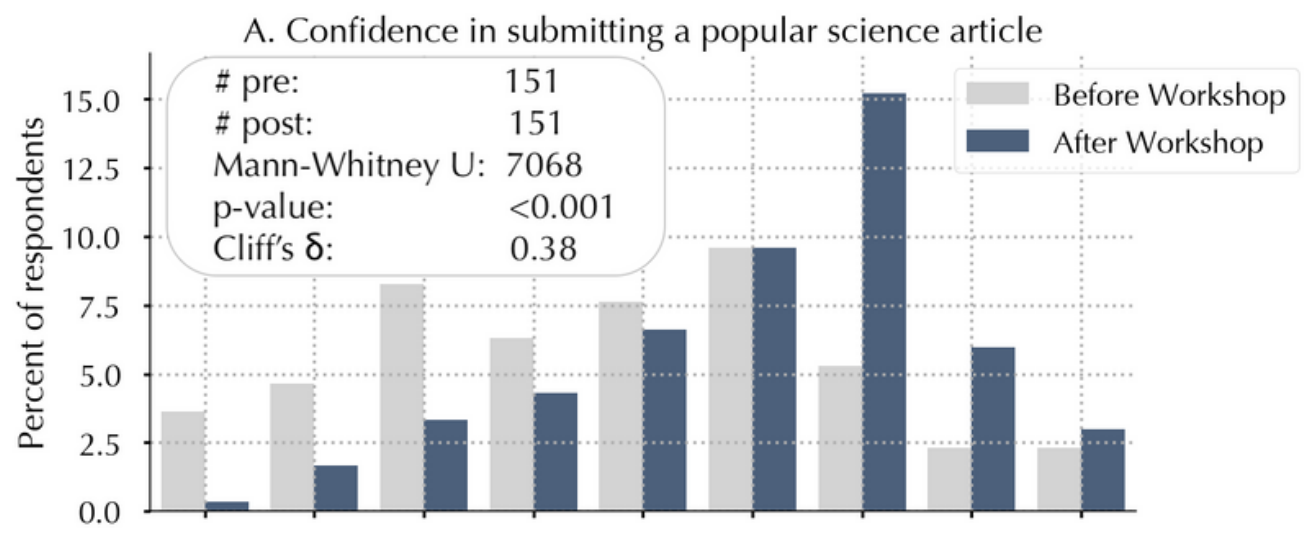

B. Confidence in communicating with the general public

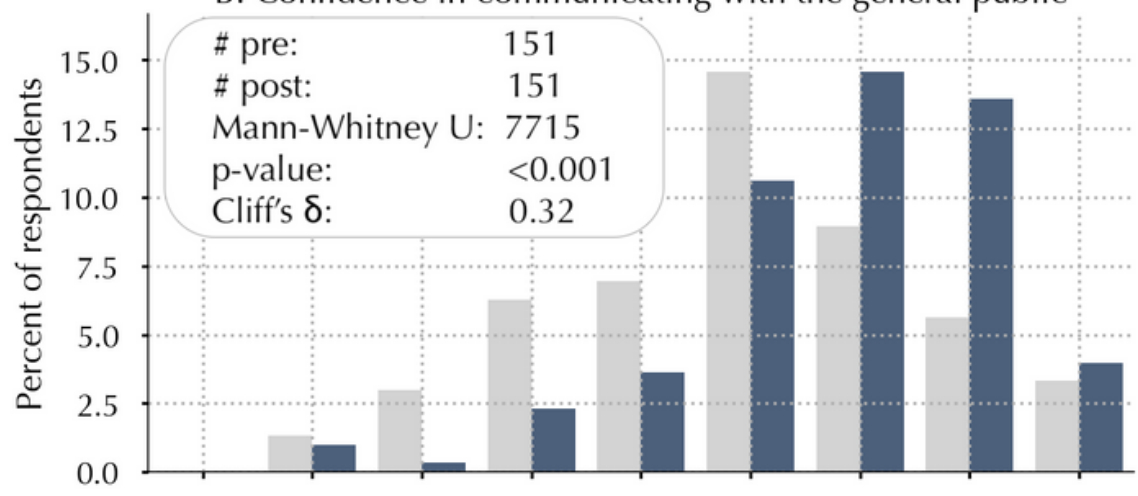

C. Confidence in communicating with other scientists

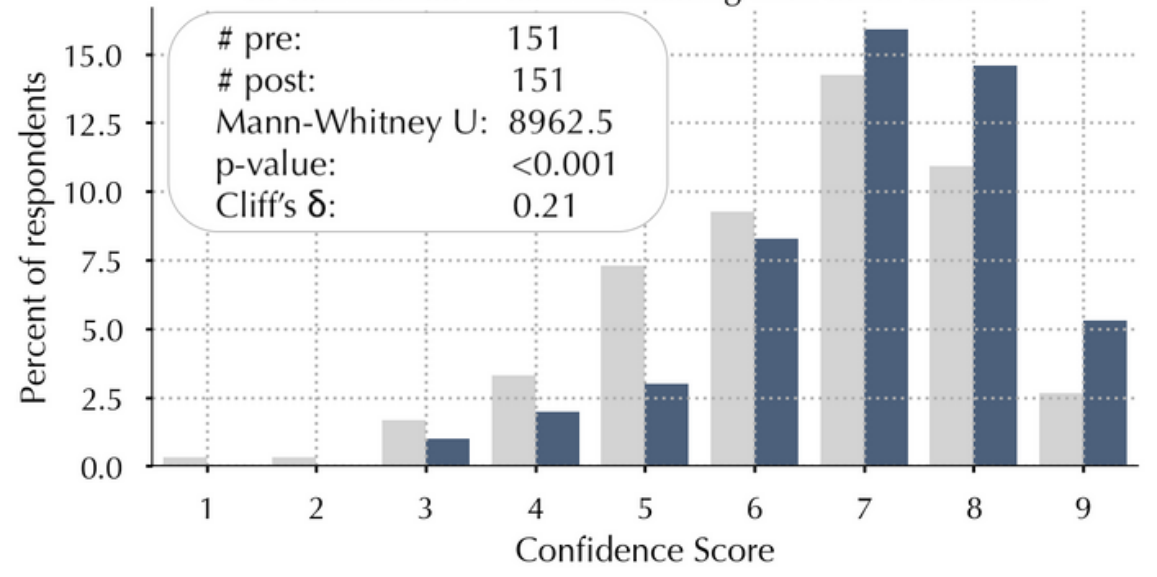

Figure 2. Attendees' self-reported confidence in A) submitting a popular science article for publication, B) communicating with the general public, and C) communicating with other scientists. Data is aggregated from three workshops spanning 2018-2020. Light gray indicates responses from before the workshop, while dark blue indicates responses from after the workshop. All three plots have p-values $<0.001$, suggesting significant improvements in confidence after attending CSC-MI. 
We also examined the change in each individual's self-reported confidence scores to assess improvement on an individual basis, based on paired data from before and after the workshop. To do so, we used the Wilcoxon signed rank test, which is an alternative to the Student's t-test for paired data when the data sample cannot be assumed to originate from a uniform distribution. The Wilcoxon signed rank test determines whether the workshop had a significant effect on attendees' individual confidence levels by testing to see if the population mean ranks differ in two sample populations, namely the two survey response samples from before and after attending CSC-MI. Differing population mean ranks would suggest that the samples originate from differing distributions. For the 151 matched pre- and post-workshop survey responses, the Wilcoxon signed rank test showed significant increases in confidence at an individual level for all three situations (submitting a popular science article $t=1653.5$, $\mathrm{p}<0.001$; communicating with the general public $\mathrm{t}=1860.0, \mathrm{p}<0.001$; communicating with other scientists $t=2247.5, p<0.001)$. Results are summarized in Figure 3 . 

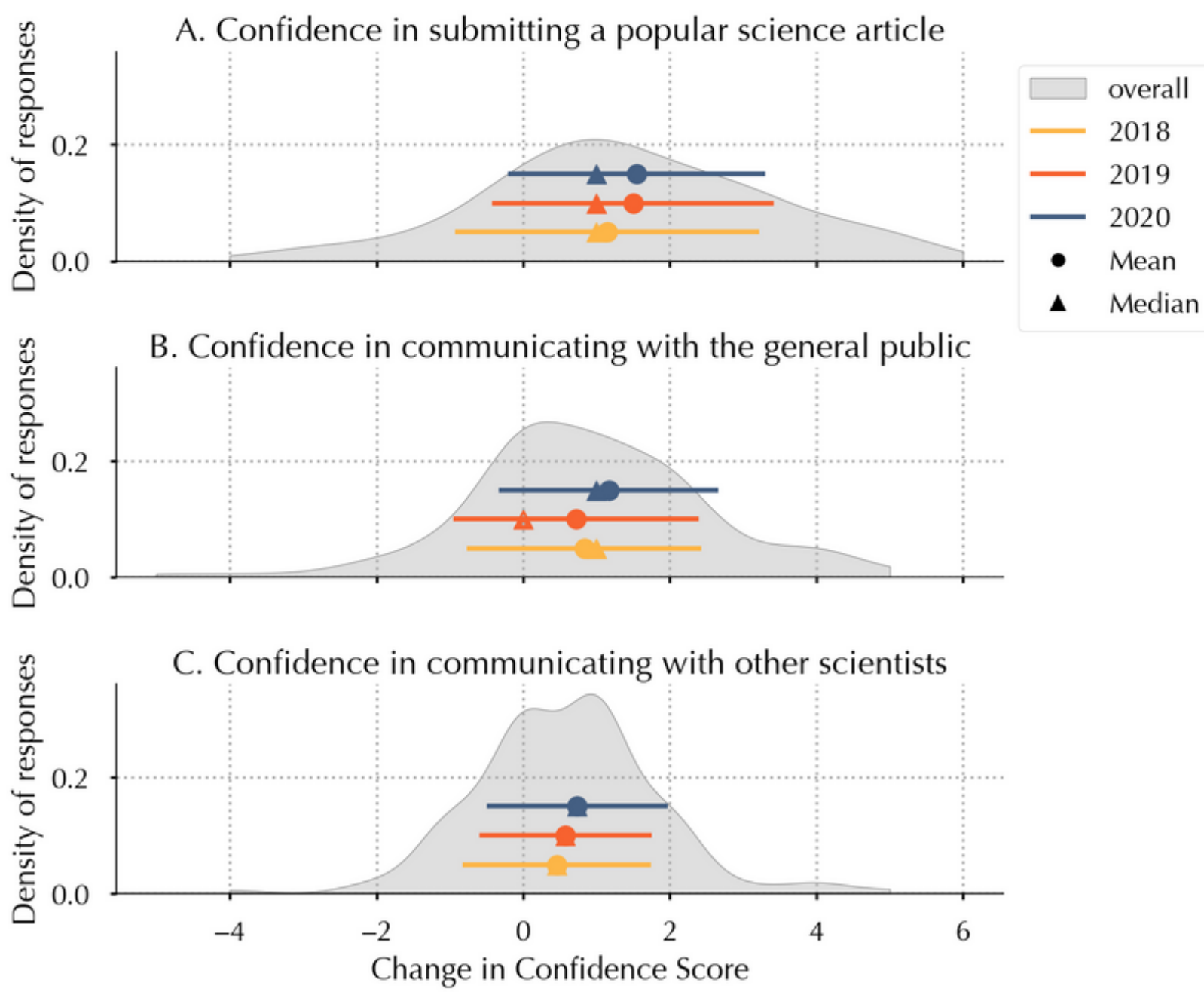

Figure 3. Changes in individual self-reported confidence communicating with various audiences as a result of attending CSC-MI. Aggregated results are shown in gray as kernel density estimations, where the $y$-axis represents the fraction of responses that fell within that range, smoothed by a Gaussian kernel. The colored bars show the mean change (circle), median change (triangles), and one standard deviation above and below the mean. The vertical placement of the colored bars is for clarity only.

Finally, participants were asked to provide four short samples of writing (2-3 sentences each) in total, which consisted of: 1) a description of their research to a general audience, prior to the workshop, 2) a description of their research to a scientific audience, prior to the workshop, and 3-4) the same description as 1 and 2, but after attending the workshop. Out of the 151 matched pre- and post-workshop survey responses, 147 attendees provided all requested writing samples. We used the Python textstat package to assess the readability and complexity of each writing sample. We 
considered an improvement in readability and complexity of the text samples to be a measure of success of the workshop. In particular, we examined the following tests:

- Flesch Kincaid Grade Level: returns the US reading grade level of a text sample by considering the lengths of sentences and complexity of words, calculated according to the equation $0.39\left(\frac{\text { total words }}{\text { total sentences }}\right)+11.8\left(\frac{\text { total syllables }}{\text { total words }}\right)-15.59$.

- Automated Readability Index: returns the US reading grade level of a text sample by considering the lengths of both the words and sentences in the sample, calculated according to the equation $4.71\left(\frac{\text { characters }}{\text { words }}\right)+0.5\left(\frac{\text { words }}{\text { sentences }}\right)-21.43$.

- Number of Difficult Words: returns the number of difficult words present in a text sample, where a "difficult word" is defined as being absent from the top 3000 most common English words. (Chall \& Dale, 1995).

- Dale-Chall Readability Score: returns the US reading grade level of a sample by considering the percentage of words classified as "difficult," together with the length of sentences, calculated according to the equation $0.1579\left(\frac{\text { difficult words }}{\text { words }} x 100\right)+0.0496\left(\frac{\text { words }}{\text { sentences }}\right) .(\underline{\text { Chall \& Dale, 1995) }}$.

Figure 4 shows the results of these tests, and Table 1 summarizes our findings. Notably, the most statistically significant change as identified by the Wilcoxon signed rank test occured in the Dale-Chall readability score for the public. While we did not find other statistically significant improvements, the mean and median scores decreased across the board, suggesting improvements in attendees' text samples after attending the workshop. 


\section{Readability Scores for Different Audiences}
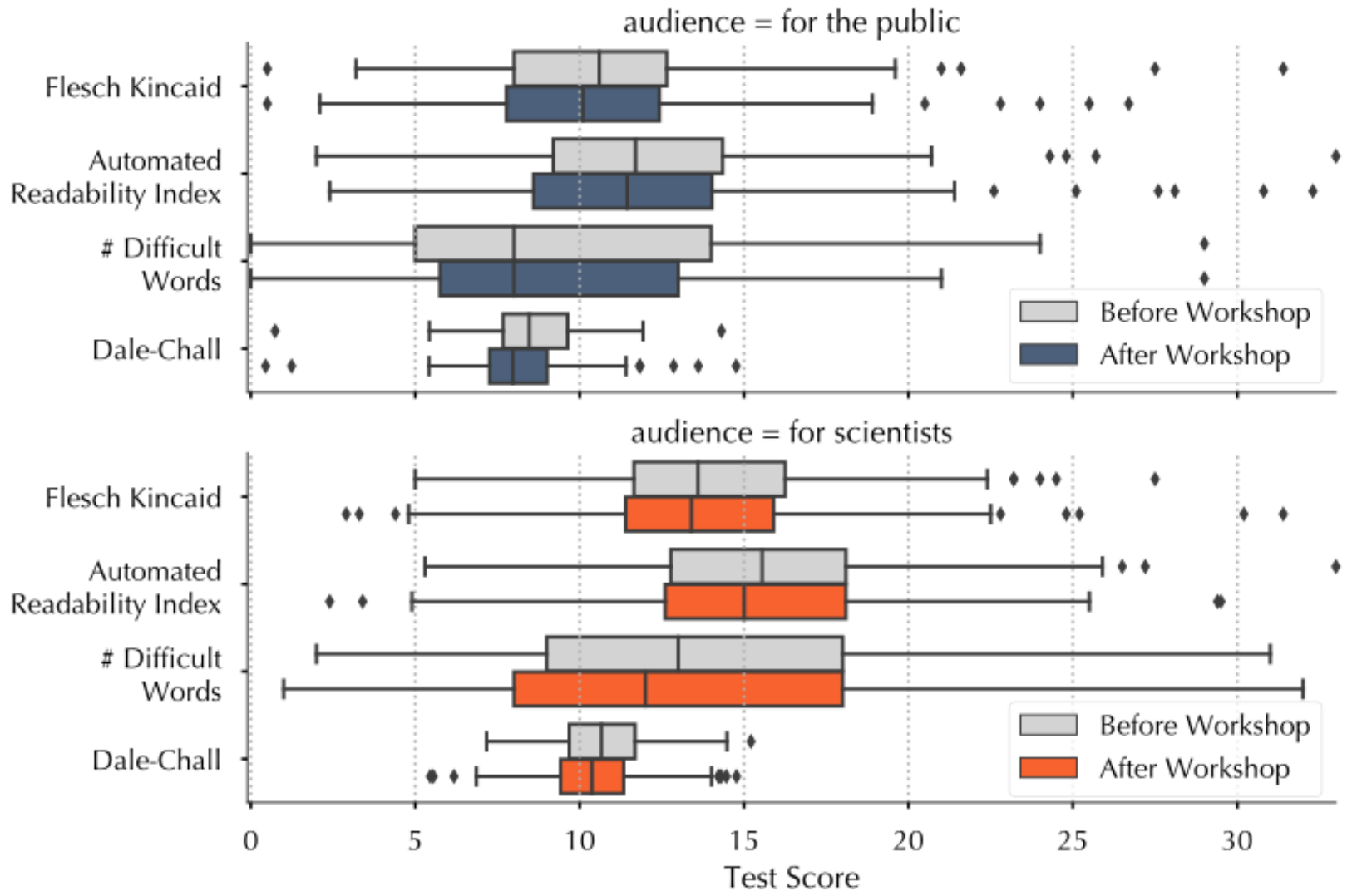

Figure 4. Text readability test scores based on attendees' 2-3 sentence text samples for public (top) and scientific (bottom) audiences. While no statistically significant decreases in reading grade level (x-axis) were identified aside from the

Dale-Chall readability score for public audiences, a general trend toward more readable text (lower test scores) is apparent by all measures after attending the workshop when compared to before.

Table 1. Numerical summary of text readability scores.

\begin{tabular}{|l|l|l|l|l|l|}
\hline Audience & Test Name & $\begin{array}{l}\text { Change in } \\
\text { Mean }\end{array}$ & $\begin{array}{l}\text { Change in } \\
\text { Median }\end{array}$ & $\begin{array}{l}\text { Wilcoxon } \\
\text { Signed Rank } \\
\text { Test Statistic } \\
\text { (.Rosner et al.,_ }\end{array}$ & \\
\hline Public & Flesch Kincaid & -0.6 & $\underline{2006})$ & p-value \\
\hline & & & -0.4 & 4900 & 0.3 \\
\hline
\end{tabular}




\begin{tabular}{|l|l|l|l|l|l|}
\hline & $\begin{array}{l}\text { Automated } \\
\text { Readability }\end{array}$ & -0.5 & -0.3 & 4941 & 0.34 \\
\hline & Difficult Words & -0.2 & 0 & 4566.5 & 0.73 \\
\hline & Dale-Chall & -0.5 & -0.4 & 4201.5 & 0.02 \\
\hline Scientists & Flesch Kincaid & -0.5 & -0.3 & 4850.5 & 0.38 \\
\hline & $\begin{array}{l}\text { Automated } \\
\text { Readability }\end{array}$ & -0.4 & -0.7 & 5027.5 & 0.51 \\
\hline & Difficult Words & -1 & -1 & 4623 & 0.29 \\
\hline & Dale-Chall & -0.4 & -0.3 & 4463 & 0.06 \\
\hline
\end{tabular}

\section{Discussion}

Within the context of a growing number of regional workshops, the local instance of CSC-MI improved the skills and confidence of attendees in science communication. The motivation behind initiating the workshop was to provide Michigan, and the midwest in general, with communication training that is largely missing from traditional university education (Cameron et al.,2015; Kuehne et al.,_2014; Stevens et al.,2019). By expanding the growing network and using the existing resources of the ComSciCon-Flagship workshop, we were able to successfully set up -- and sustain for three years and counting -- a yearly conference that is designed with the needs and interests of the local community in mind.

Attendee's demographics were diverse on many levels. We were excited to be able to provide so many attendees with training to help them communicate their science more effectively, regardless of career path. The application questions focused on applicants' motivations for wanting to attend, in addition to evaluating their current science communication skills in the form of a small writing sample. ComSciCon chapter workshops typically provide training to new science communicators, because conferences in general can reward applicants with already impressive resumes and contribute to an ever-increasing gap in opportunity. We therefore focused on admitting attendees that did not already have a significant amount of experience with science communication, to promote equal access to learning opportunities. This approach is reflected in Figure 1, where most of the attendees had less than two years of science 
communication experience, and less than $20 \%$ of all the 144 attendees surveyed had over four years experience.

In addition to experience, diversity and representation were important to us when admitting applicants. This included gender, ethnicity, and race, in addition to discipline of study (Figure 5) and university attendance. While this section of the application was not weighted heavily, it helped us ensure that the people who attended the conferences came from universities from around the state of Michgian and the Midwest, had a range of scientific experience, and represented diverse backgrounds. 


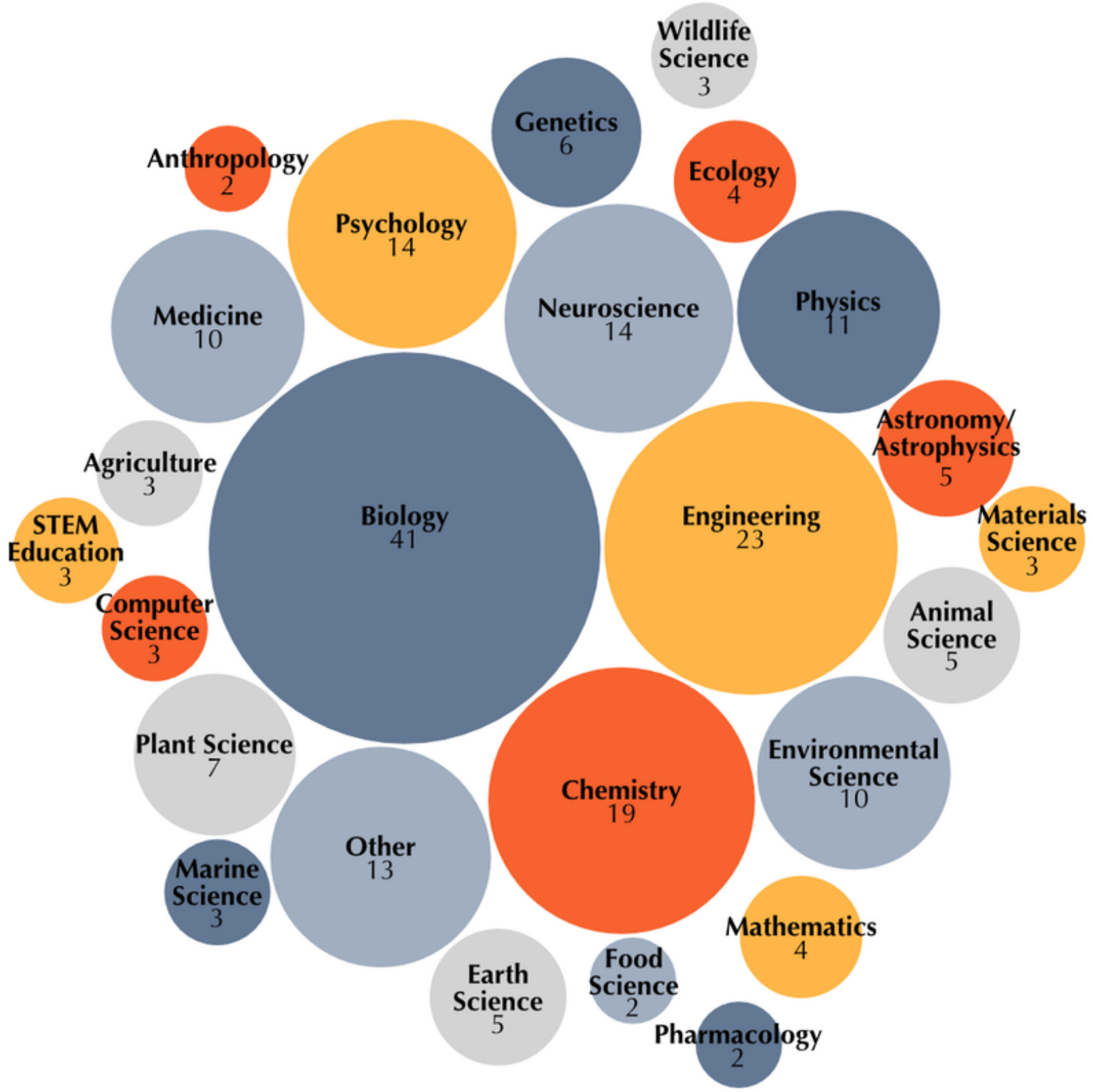

Figure 5. The scientific fields represented by the 144 attendees who completed the demographics portion of the workshop surveys. The area of each circle scales by the number of responses in that category. Because some attendees identified as belonging to more than one scientific field, the total response count is 215 . "Other" consolidates scientific fields for which there was only one response and includes: aeronautics, archaeology, biophysics, computational biology, data science, hydrology, journalism, kinesiology, nuclear science, remote sensing, social work, sociology, and statistics. 
Confidence in science communication increased. Across the board, attendees' confidence in their ability to communicate with different audiences increased. This was determined by correlating attendee's self-reported confidence in their pre- and postconference surveys. We inquired about three ways of communicating science: in a popular science article (Figure 2A), talking with the public (Figure 2B), and talking with other scientists (Figure 2C). Confidence increased both during individual conferences during 2018, 2019, and 2020 (Supplemental Figure 1) in addition to aggregating the data across the three years (Figure 2),, with statistically significant increases and $p$-values $<0.01$ for all plots except communicating with scientists when the 3 years are analyzed separately. This is likely because attendees' confidence was higher to begin with when conversing with their peers. Since our conference focused on communicating science with the public, we were not surprised to find that attendees' confidence in communicating with other scientists did not increase as significantly.

The biggest change in self-reported confidence (measured by the highest Cliff delta score) was in participants' confidence in submitting a written piece to a popular science article, likely because the conference placed a high emphasis on producing a written piece. Before the conference, attendees wrote an initial draft of a popular science piece, which was then edited by peers in small groups. At the conference, attendees then received a second round of feedback from "expert editors," who were typically pulled from invited panelists and session leaders and who had experience in science writing and editing. Attendees were then encouraged to submit their articles for publication. This strong focus on communicating science through writing explains why the largest difference in self-reported confidence was for submitting a popular science article. Indeed, many attendees pitched and published their written pieces in well-known outlets, including Discover Magazine and Natural History magazine, among others after the conference ComSciCon partners with Natural History_ magazine on a special print issue, n.d. ; Koenig, 2020).

Additionally, we were pleased with the overall increases for ComSciCon-MI 2020, since the two-day conference (usually in-person) had to be shifted entirely online due to the COVID-19 pandemic. Despite the limitations of online conferences, like limited networking opportunities and "Zoom fatigue," we still measured increases in attendees' confidence in communicating science to a variety of audiences.

Readability of attendees' science writing showed a trend towards improvement. Across the board, the readability of attendees' 2-3 sentence text samples for both 
public and scientific audiences showed a clear trend towards improvement (Figure 4). This was determined by computing and comparing several readability scores for the pre- and post-conference writing samples. We saw a statistically significant improvement in the readability of the writing samples for the public as measured by the Dale-Chall readability score, while all other scores showed clear but nonsignificant improvement, and thus a trend towards improved readability. Providing training to help early career scientists improve the readability of their science writing across various types of audiences was a primary goal, so the improvements seen in the text samples for both general public and scientific audiences highlighted the success of the conference.

Indeed, each conference hosted multiple workshops and sessions that were dedicated to increasing accessibility and inclusivity of science writing. The Write-A-Thon provided in-depth and personalized feedback of the attendees' writing projects, and participants noted that the interaction with expert editors was valuable for both their confidence in their communication abilities, as well as the quality of their writing. In addition, several interactive workshops focused on improving the quality of science writing across disciplines and audience types, including "Science Journalism 101,"News and Feature Writing for Scientists," "Inclusive Communication Practices," and "Communication Fundamentals." Often, these workshops and the Write-A-Thon received the highest ratings in our post-conference surveys, indicating that training in clear and effective communication is widely sought and valued by early career scientists.

Core strengths of CSC-MI. According to feedback from our post-workshop surveys, the CSC-MI conference had three main strengths that highlight the current training needs and priorities of early career scientists:

(1) decreasing jargon and increasing accessibility of language,

(2) exposing attendees to opportunities and a community of other science and research professionals who value effective science communication, and

(3) active experience with and expert feedback on science writing.

For many attendees, this conference served as their introduction to science communication training and provided access to tools and peers that would continue to support their communication endeavors for years to come. When receiving direct feedback, one testimonial stated that, "ComSciCon-MI 2020 acted as a crash course in 
SciComm. It was the perfect opportunity for me to start writing about topics outside of my research, learn about new opportunities in science, and network with others in SciComm." Indeed, this single testimonial highlights all three of the core strengths of the conference: communication training, access to opportunities and a network, and hands-on writing experience.

Each conference had multiple workshops focused on decreasing jargon and intentionally using inclusive and accessible language, including "Half-Life Your Science," “Inclusive Communication Practices," "Navigating Difficult Conversations," and "Communication Fundamentals." These workshops aimed to provide concrete strategies and practices that attendees could use to tailor their communication to various audiences and formats, while maximizing clarity and inclusivity. Attendees often rated these sessions highest in their post-workshop surveys, providing direct feedback that highlighted the importance of this type of training. One such testimonial is shown below.

"Inclusive resources provided good resources and discussion for trying to include more people in your presentation. I think everyone should be made aware of these factors if they ever want to present."

Another main strength of this conference is in providing access to opportunities within the community of science communication for attendees. For many early career scientists, much of their time and training will be spent in a research setting focused on data collection and analysis rather than external communication. As such, trainees can be isolated from the communities that engage with non-research priorities. CSCMI serves as the gateway for attendees to enter the vast science communication community, meeting both early career peers and communication professionals that will serve as a network for the remainder of their professional careers. Direct feedback showed that the networking aspects of the conference alone were of great value to attendees, with testimonials shown below.

"ComSciCon was a great way to meet other people interested in sharing their science, as well as getting expert advice on the best ways to do it!"

"The best part about this event is you have people from different streams of science, so there is a lot to soak in to improve your communication."

Lastly, the Write-A-Thon component of the conference served as an opportunity for participants to gain hands-on experience and expert feedback on their own personal 
projects. As part of their participation in CSC-MI, attendees must write an original piece on a scientific topic of choice that then undergoes several rounds of both peer editing and feedback from a professional science communicator. This guarantees that all participants will have the opportunity to practice writing for a general audience and will leave the conference with a polished piece ready for publication. Indeed, our attendees often value the Write-A-Thon editing sessions higher than all other sessions. This is shown in our many testimonials, with three examples listed below.

"I really appreciated the strict deadlines [for the Write-A-Thon] because they helped me to stay on track.I'm really glad that I finally got these ideas down on paper and I'm excited to look for venues to pursue them further!"

"I loved the breakout session where we got feedback on our drafts. It was so cool to chat with fellow attendees and to get feedback from a real science writer!"

"The collaborative nature of peer reviewing with both my fellow graduate students and the professor who volunteered to contribute was unbelievably valuable and I plan to further develop my writing and proffered piece with their comments and recommendations in mind."

\section{Conclusions}

As one of the only ComSciCon workshops in the Midwestern United States, CSC-MI provides a unique opportunity for early career scientists from a variety of backgrounds to gain science communication experience at a formative time in their careers. As such, it is important to evaluate the impact and efficacy of conference programming. From data obtained from pre- and post-conference surveys, we show that there is a measurable impact on science communication skills for attendees of the local CSC-MI conference. Targeted science communication training with ComSciCon for early career researchers in Michigan has increased attendees' self-reported confidence in communicating with a variety of audiences and has improved readability of text samples. Aside from these measurable benefits, early career scientists in this program also have opportunities to gain hands-on experience in science communication, publish their science communication work, and network with peers and science communication professionals.

ComSciCon workshops fill an important gap in the training of early career scientists. As more ComSciCon workshops become established around the world, it will be 
important to continue to evaluate the efficacy of these programs. Especially with the growing distrust of science and scientists in public spaces, effective scientific communication that can both be understood and persuade and prioritize audiences is increasingly important.

\section{Acknowledgements}

Thanks to ComSciCon Leadership and CSC-MI committees for guidance and organization the past three years. We would also like to thank our sponsors at Michigan State University (Physics \& Astronomy, Office of the Senior VP for Research \& Innovation, Microbiology \& Molecular Genetics, Pharmacology \& Toxicology, Graduate School, Ecology/Evolution/Behavior, Genetics, Animal Science, Council of Graduate Students, Biochemistry \& Molecular Biology, Integrative Biology, MSU SciComm) and at the University of Michigan (Office for Graduate \& Postdoctoral Studies, Physics, Astronomy, Michigan Science Writers, Life Sciences Institute, Neuroscience Graduate Program, Bioartography, Society for Women in Physics, Chemistry, Rackham Graduate School, Women in Science \& Engineering, Center for Educational Outreach).

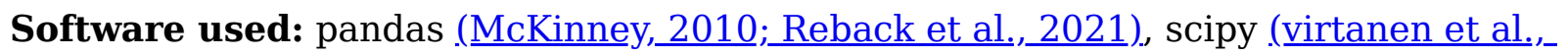
2020), matplotlib (ㅂuter, 2007), textstat (https://pypi.org/project/textstat/), seaborn (Waskom, 2021).

\section{Citations}

1. Collier, R. (2017). Facts not enough to change minds about health myths. CMAJ: Canadian Medical Association Journal = Journal de l'Association Medicale Canadienne, $189(\underline{46})$, E1430.

2. Hayhoe, K. (2018). When facts are not enough. Science, $\underline{360}(\underline{6392}), \underline{943-943 .}=$ 3. Kabat, G. C. (2017). Taking distrust of science seriously. EMBO Reports, 18(7), $\underline{1052-1055 .}$.

4. Rutjens, B. T., Heine, S. J., Sutton, R. M., \& van Harreveld, F. (2018). Chapter Three - Attitudes Towards Science. In J. M. Olson (Ed.), Advances in Experimental Social Psychology_(Vol. 57,_pp. 125-165). Academic Press. 
5. Bilandzic, $\underline{\text { H. }}, \underline{\text { Kinnebrock}}, \underline{\text { S. }}$, \& Klingler, M. (2020). The emotional effects of science narratives: A theoretical framework. Media and Communication, $\underline{8}(\underline{1}), \underline{151-}$ 163.

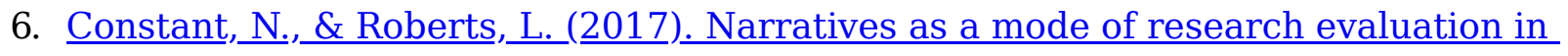
citizen science: understanding broader science communication impacts. Journal of Science Communication., 16(4), A03.

7. Shermer, M. (2017). How to convince someone when facts fail. Scientific American, $1 . \pm$

8. Brownell, S. E., Price,_J. V., \& Steinman, L. (2013). Science Communication to the General Public: Why We Need to Teach Undergraduate and Graduate Students this Skill as Part of Their Formal Scientific Training. Journal of Undergraduate Neuroscience Education: JUNE: A Publication of FUN, Faculty for Undergraduate Neuroscience, 12(1), E6-E10.

9. Denecke, D.,Feaster, K. , \& Stone, K. (2017). Professional development: Shaping effective programs for STEM graduate students. Washington, DC: Council of Graduate Schools. $\triangleq$

10. Kuehne, L. M., Twardochleb, L. A., Fritschie, K. J,,Mims, M. C., Lawrence, D. J,,Gibson, P. P., Stewart-Koster, B., \& Olden,J. D. (2014). Practical science communication strategies for graduate students. Conservation Biology: The Journal of the Society for Conservation Biology, 28(ㅁ), 1225-1235. $\_$ 11. Dilger, A. C., \& McKeith, F. K. (2015). Training_graduate students to communicate science to broad audiences. Animal Frontiers, $\underline{5}(\underline{3}), 60-63$. 12. Hatcher, R. L. (2014). Why is it important to know how academic programs prepare graduate students for practicum training? In PSycEXTRA Dataset. https://doi.org/10.1037/e545542014-001

13. Laursen, S. L., Thiry, H., \& Liston, C. S. (2012). The impact of a university-based school science outreach program on graduate student participants' career paths and professional socialization. Journal of Higher Education Outreach and Engaggement, 47-78.

14. Fiske, S. T., Cuddy, A. J. C., \& Glick, P. (2007). Universal dimensions of social cognition: warmth and competence. Trends in Cognitive Sciences, $11(2)$, 77-83. 
15. Kahan, D. M. (2017). Misconceptions, Misinformation, and the Logic of IdentityProtective Cognition. https://doi.org/10.2139/ssrn.2973067

16. Renn, O., Levine, D., Kasperson, R. E., \& Stallen, P.J. M. (1991). Communicating_ risks to the public. Credibility and Trust in Risk Communication.

17. Saffran, L., Hu, S., Hinnant, A., Scherer, L. D., \& Nagel, S. C. (2020). Constructing and influencing_perceived authenticity in science communication: Experimenting with narrative. PloS One, 15(1), e0226711. $\_$ 18. Siegrist, M.,_Cvetkovich, G., \& Roth, C. (2000). Salient value similarity, social trust, and risk/benefit perception. Risk Analysis: An Official Publication of the Society for Risk Analysis, 20(3), 353-362. 19. O’Keeffe, K. \& Bain, R. (2018). ComSciCon-Triangle: Regional Science Communication Training for Graduate Students. Journal of Microbiology \& Biology Education: JMBE, 19(1). https://doi.org/10.1128/jmbe.v19i1.1420

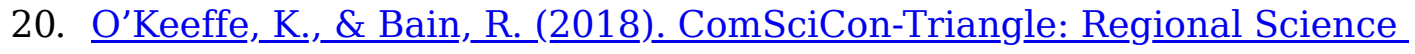
Communication Training for Graduate Students. Journal of Microbiology \& Biology Education: JMBE, 19(1). https://doi.org/10.1128/jmbe.v19i1.1420 21. Chall,_J. S., \& Dale, E. (1995). Readability Revisited: The New Dale-Chall Readability Formula. Brookline Books. $\triangleq$ 22. Chall,_J. S.,\& Dale,E. (1995). Readability Revisited: The New Dale-Chall Readability Formula. Brookline Books. 23. Rosner, B., Glynn, R. J., \& Lee, M.-L. T. (2006). The Wilcoxon signed rank test for paired comparisons of clustered data. Biometrics, 62(1), 185-192.

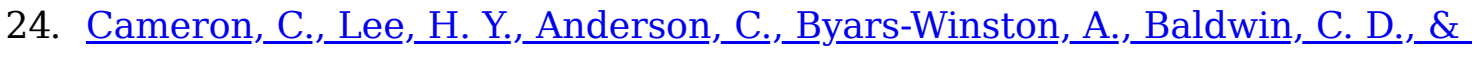
Chang, S. (2015). The Role of Scientific Communication Skills in Trainees' Intention to Pursue Biomedical Research Careers: A Social Cognitive Analysis. CBE-Life Sciences Education, 14(4), ar46. 25. Kuehne, L. M., Twardochleb, L. A., Fritschie, K. J,,Mims, M. C., Lawrence, D. J., Gibson, P. P., Stewart-Koster, B., \& Olden,.J. D. (2014). Practical science communication strategies for graduate students. Conservation Biology: The Journal of the Society for Conservation Biology, 28(5), 1225-1235. 


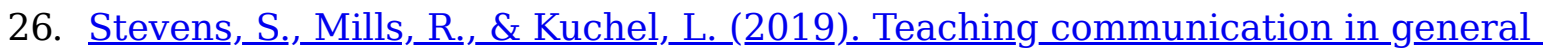
science degrees: highly valued but missing the mark. Assessment \& Evaluation in Higher Education, 44 $(\underline{8})$, ,1163-1176. $\doteq$

27. ComSciCon partners with Natural History magazine on a special print issue. (n.d.). Retrieved July 30, 2021, from https://comscicon.com/news/comscicon-partnersnatural-history-magazine-special-print-issue $\subseteq$

28. Koenig, L. (2020, November 5). Parrots live in New York city. Here's how they make it in the urban jungle. Discover Magazine. https://www.discovermagazine.com/planet-earth/parrots-live-in-new-york-city-hereshow-they-make-it-in-the-urban-jungle $\underline{\underline{u}}$

29. McKinney, W. (2010). Data Structures for Statistical Computing in Python. Proceedings of the 9th Python in Science Conference. Python in Science Conference, Austin, Texas. https://doi.org/10.25080/majora-92bf1922-00a

30. Reback,_J,_jbrockmendel, McKinney, W., Van den Bossche,_J.,_Augspurger, T., Cloud, P.,_Hawkins, S.,_gfyoung, Sinhrks, Roeschke, M., Klein, A., Petersen, T.,

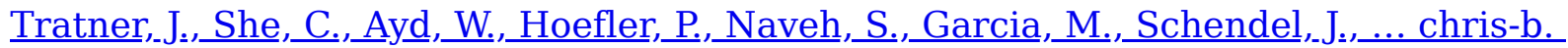
(2021). pandas-dev/pandas: Pandas 1.2.5. https://doi.org/10.5281/zenodo.5013202

31. Virtanen, P., Gommers, R., Oliphant, T. E.,_Haberland, M., Reddy, T., Cournapeau, D.,Burovski, E.,Peterson, P., Weckesser, W., Bright,_J,,van der Walt, S. J., Brett,_M.,_ Wilson,_J.,Millman, K. J., Mayorov, N., Nelson, A. R. J.,Jones, E., Kern, R., Larson, E.,_ ... SciPy 1.0 Contributors. (2020). SciPy 1.0: fundamental algorithms for scientific computing in Python. Nature Methods, 17 (7) $\underline{3}), \underline{261-272 .}$.

32. Hunter,_J. D. (2007). Matplotlib: A 2D Graphics Environment. Computing in Science \& Engineering, 9(3), , 90-95.

33. Waskom, M. (2021). seaborn: statistical data visualization. Journal of Open Source Software, $6(\underline{60}), \underline{3021 .}$. 